\title{
The Study of the Impact of E-commerce Participator on Online Reputa- tion Formation
}

\author{
Zhaoji $\mathrm{Yu}^{1, *}$ and Chuang $\mathrm{Wei}^{2}$ \\ ${ }^{1}$ School of Management, Shenyang University of Technology, Shenyang, 110870, China; ${ }^{2}$ Shenliao Western Road 111\#, \\ Shenyang, 110870, 15998806198, China
}

\begin{abstract}
Nowadays, with e-commerce developing by leaps and bounds, online reputation problem is one of the most important problems which need to be solved. The study of the impact of e-commerce participator on online reputation formation can provide decision basis for the parties and constraint their behavior. Through the definition of the e-commerce participator, studying e-commerce subject to find out which can affect online reputation formation to a large degree. This paper finds the influential factors by using literature theory analysis and the questionnaire. Via the construction of the six-dimensional factors index system of 24 quantitative indicators, design model of online reputation formation influenced by E-commerce participator. In empirical research, questionnaires be made again to collect data, the model has been revised 3 times to work out that it has 13 index with 5 parts. Finally draw the appropriate conclusions for each of the main effects on e-commerce online reputation formation.
\end{abstract}

Keywords: Electronic commerce, empirical analysis, impact study, online reputation.

\section{INTRODUCTION}

With the development of the information technology and the popularization of the Internet, the rise of the e-commerce has changed business pattern of the traditional commercial activities [1]. Comparing with traditional business pattern, ecommerce deepens segregation degree of time and space for each business side. This makes two sides cannot identify each side identification, so that the initial trust cannot be built $[2,3]$. And then this accelerates the transformation of two sides' form and contents of trust. The lagged development of online reputation has become the main factor which restricts efficient and health development of e-commerce [4].

Recently, scholars who are in domestic and overseas have given more interest to the factors which influence online reputation [5-9]. Mcknight\&Chervany presented the theoretical model of formation process of reputation behavior. They believed that the formation of the reputation includes change process of from reputation faith to reputation willing and then to the reputation behavior [10]. Yanchun Zhu Liu, and Wei Zhang presented simulation research on the base of model building [11]. Dengke Yuan constructed evaluation model of the risk of online reputation on the base of game theory [12].

Nowadays, the study of the online reputation and its influencing factors mainly focuses on the quantitative analysis by constructing model [13-15]. Most put emphasis on explaining how online reputation influences e-commerce and what kind of element influences online reputation. However,

*Address correspondence to this author at the School of Management, Shenyang University of Technology, Shenyang, 110870, China; Tel: 15909810777; Fax: (024) 25496545;

E-mail: shengchanjihua999@vip.sina.com there is no a systematic interpretation about how online reputation generates, also no explain when and where generate during the transaction process. Mostly, we use deductive theory to choose influencing factors. When verifying the selection of influencing factors, we mainly use the empirical research, but the reliability of the data of empirical research are not easy to control.

E-commerce participators of online transaction have different characteristics. So each subject has different influence on the online reputation [16]. Alreck and Settle study the online shopping behavior from the aspect of time-saving. They found that online shopping was believed can save more time than traditional shopping pattern. However, in order to save time, the frequency that customers who choose to shop online have no relation with his or her level of time pressure, but significantly correlate with the time of online and work [17]. From the side of influence of seller in online reputation, Shujuan Zhang et al., believes that seller using modification of language and semantic would affect online reputation [18].

In the study of the effect of e-commerce participator in online reputation, systematic and gathered study of influence research of each subject on online reputation is dispersed. Meanwhile, every researcher has different partition about the e-commerce subjects. Without a unified specific name, most researches are incomplete. But isolation of each subject would make repeat calculation of some influencing factors or thoughtlessness of interaction.

To study the influence of e-commerce participator on online reputation has a significant function on improving reputation degree of related trade subjects in e-commerce, ensuring a safer online transaction, improving amount of online transaction and so on [19]. In this paper, the subjects of 
Table 1. The influence factors of literature theory analysis.

\begin{tabular}{|c|c|c|}
\hline Subjects & Representatives of Researchers & Influencing Factors \\
\hline \hline Seller & $\begin{array}{c}\text { GuangXing Song } \\
\text { Zhaoji Yu, } \text { et al. }\end{array}$ & $\begin{array}{c}\text { Scale and figure, conformity of goods description, after-sales service, interaction degree, per- } \\
\text { sonal qualities, existing judgment, accumulate reputation, fake good reputation, hired delete, } \\
\text { amount of stocks }\end{array}$ \\
\hline Buyer & $\begin{array}{c}\text { Shuxian Ji, } \\
\text { Minli Jin, et al. }\end{array}$ & $\begin{array}{c}\text { Experience, tend to trust, external recommend, risk perception, personal qualities, income, times } \\
\text { of transaction, money of transaction, vicious mutual evaluation, public praise, ability of commu- } \\
\text { nication, pay in time }\end{array}$ \\
\hline Website & $\begin{array}{c}\text { Xuefeng Zhao } \\
\text { Xiangyang Liu, et al. }\end{array}$ & $\begin{array}{c}\text { Convenience, authentication system, judgment system, information safety, dispute resolution } \\
\text { mechanism }\end{array}$ \\
\hline Logistics & $\begin{array}{c}\text { Minli Jin, } \\
\text { Fanhuan Gong, } \text { et al. }\end{array}$ & $\begin{array}{c}\text { Convenience, information check, track system, service pattern, force majeure, measure of com- } \\
\text { pensation, punctuality, quality of transportation, update rate of transportation facilities }\end{array}$ \\
\hline Govt & Yuan Li, et al. & Law environment, punishment, guarantee service platform, amount of base, online police \\
\hline Supplier & Yang Ji, et al. & Price competition, quality of goods, on time delivery, amount of stocks \\
\hline
\end{tabular}

Table 2. The influence factors of the questionnaire.

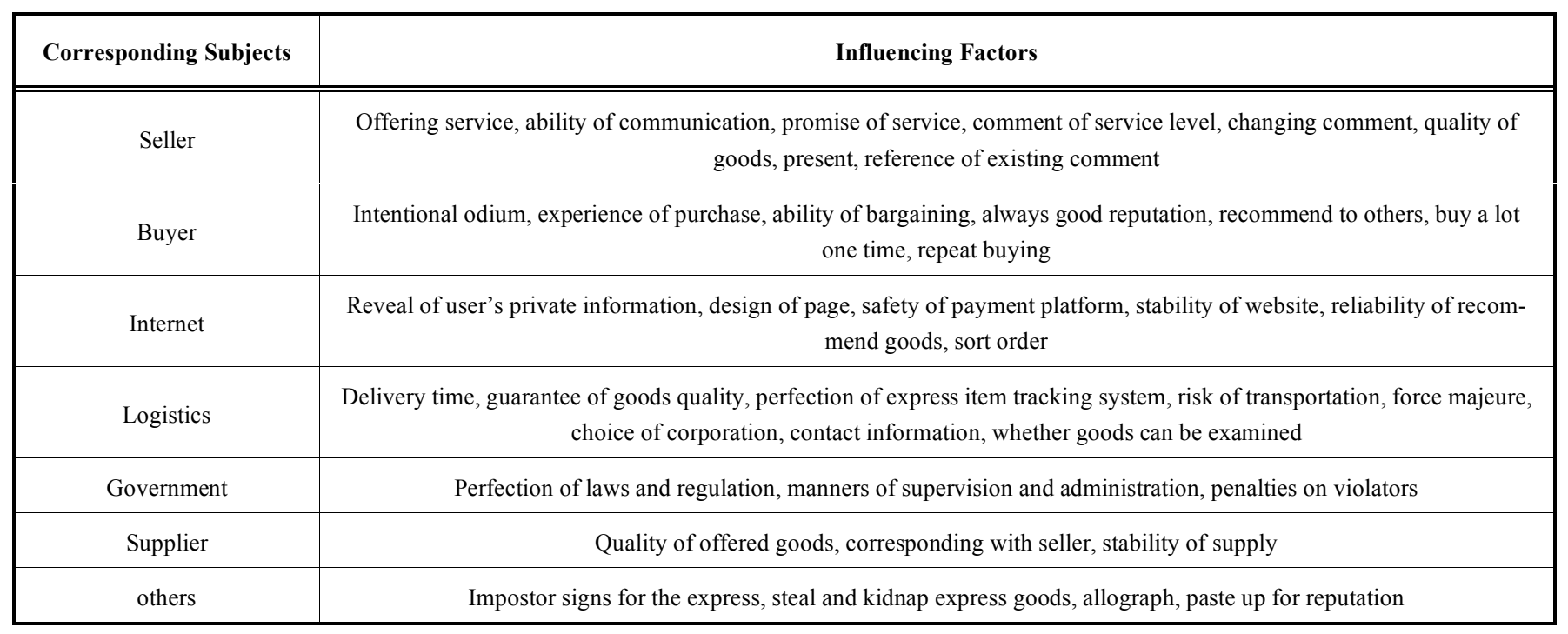

e-commerce are defined as direct subjects (buyer, seller) and indirect subjects (websites, Logistics, government, et al.,). Based on these views, this paper perfects the theory and examines practice. It focuses on the study of the influence of ecommerce participator in online reputation formation. And it analyzes quantitative index of each subject for the reference and perfection of related subjected.

\section{INFLUENCE MODEL OF E-COMMERCE PARTICI- PATORS IN ONLINE REPUTATION FORMATION}

The Analysis of Influencing Factor of E-commerce Participator in Online Reputation Formation

Under the guidance idea of gathering all points, the paper summarizes influencing factors of each e-commerce subject on the formation of online reputation. Since there exists regional difference on the development of e-commerce, we choose literatures of scholars of mainland China as main reference, as shown in Table $\mathbf{1}$.
In order to understand the influencing factors of ecommerce subjects in formation of online reputation roundly, on the basis of extracted influencing factors by using theoretical analysis, according to the analysis of inquiry data by using questionnaire survey, the interviewees propose a more comprehensive supplement which aims at the influence of e-commerce on formation of online reputation, as in Table 2.

As shown in above Table $\mathbf{2}$, most of influencing factors corresponds with the result which comes from literatures arrangement. There are some factors which have never been mentioned in former literatures, like force majeure of logistics, etc. What needs to be noticed is that there are some answers like impostors. But these all belong to principal part of accidental events. Impostors belong to the poor regulation of logistics. Brushing the credibility belongs to fraudulent behavior of sellers.

According to the literature theory analysis and questionnaire arrangement, we combined same or similar factors to- 
Table 3. The index system for online reputation formation influenced by E-commerce participator.

\begin{tabular}{|c|c|c|c|}
\hline \multirow{25}{*}{$\begin{array}{c}\text { Online reputa- } \\
\text { tion formation } \\
\text { influenced by } \\
\text { E-commerce } \\
\text { participator }\end{array}$} & Factors & Measurement Index & Measurement Meaning \\
\hline & \multirow{6}{*}{ Seller } & VOLAMOUNT & Reflecting situation of scale, capital turnover and stock \\
\hline & & Cost performance of offered goods & Reflecting situation of goods conformity and price \\
\hline & & Valid communication frequency & Reflecting ability of communication and bargaining \\
\hline & & Accumulated reputation & Reflecting personal qualities, influencing decision of buyer \\
\hline & & Good reputation of service & Including after sale, interaction degree and feedback \\
\hline & & Fraud frequency & Measuring frequency of changing comment \\
\hline & \multirow{5}{*}{ Buyer } & Purchase frequency & Reflecting experience of consume willing and income \\
\hline & & Valid communication frequency & Reflecting ability of bargaining and risk perception \\
\hline & & Accumulated reputation & Reflecting personal qualities and in time payment \\
\hline & & Fake comment frequency & Measuring intentional odium, habit of comment good \\
\hline & & Frequency of spread-Recommend & Measuring word -of -mouth effect and situation of repeat buying \\
\hline & \multirow{4}{*}{ Website } & Perfection of security system & Including situation of authentication, information and security of payment \\
\hline & & Reliability of basic design & Stability and convenience \\
\hline & & Frequency of success recommend & Sort order, display ads, history information \\
\hline & & Number of dispute dissolution & Investigating service, rules and evaluation system \\
\hline & \multirow{4}{*}{ Logistics } & Timely delivery & Investigating time of delivery, choice of transportation facilities \\
\hline & & Perfection of information system & Return of goods, perfection of express item tracking system \\
\hline & & Frequency of compensation payout & Frequency of compensation on inevitable force and accident \\
\hline & & Frequency of good reputation of service & Quality assurance, service attitude, situation of goods examine \\
\hline & \multirow{3}{*}{ Govt } & Number of laws and regulations & Investigating perfection of laws and regulations and penalties \\
\hline & & Number of online police & $\begin{array}{c}\text { Formation of evaluation system and degree of supervision and administra- } \\
\text { tion }\end{array}$ \\
\hline & & Number of base and platform & Investigating investigation of government and strategic coordination \\
\hline & \multirow{2}{*}{ Provider } & Cost performance of offered goods & Investigating quality of goods and primary pricing \\
\hline & & Frequency of timely delivery & Investigating stock and personal quality \\
\hline
\end{tabular}

gether and presented these factors by using imitate ration disposal. Table $\mathbf{3}$ shows the target system of factors.

\section{Construction of Influence Model for Online Reputation Formation Influenced by E-commerce Participator}

According to aforesaid analysis, the paper constructs influence model for online reputation formation influenced by Ecommerce participator, as shown in Fig. (1).

\section{THE RESEARCH OF DEMONSTRATION}

\section{Hypothesis}

According to the model that E-commerce participator influence the formation of online reputation., the main part of e-commerce, which influences the formation of online reputation, includes 6 factors: seller, buyer, website, logistics, government and provider. Therefore, this paper offers the following hypothesis:
H1: The seller will influence the formation of the online reputation observably.

$\mathrm{H} 2$ : The buyer will influence the formation of the online reputation observably.

H3: The website will influence the formation of the online reputation observably.

H4: The Logistics will influence the formation of the online reputation observably

H5: The government will influence the formation of the online reputation observably.

H6: The supplier will influence the formation of the online reputation observably.

On the side of seller, the times of clinching deals, offering the commodity's cost performance, the frequency of efficient communication, the seller's accumulation of credit standing value, the good comments of services and the fre- 


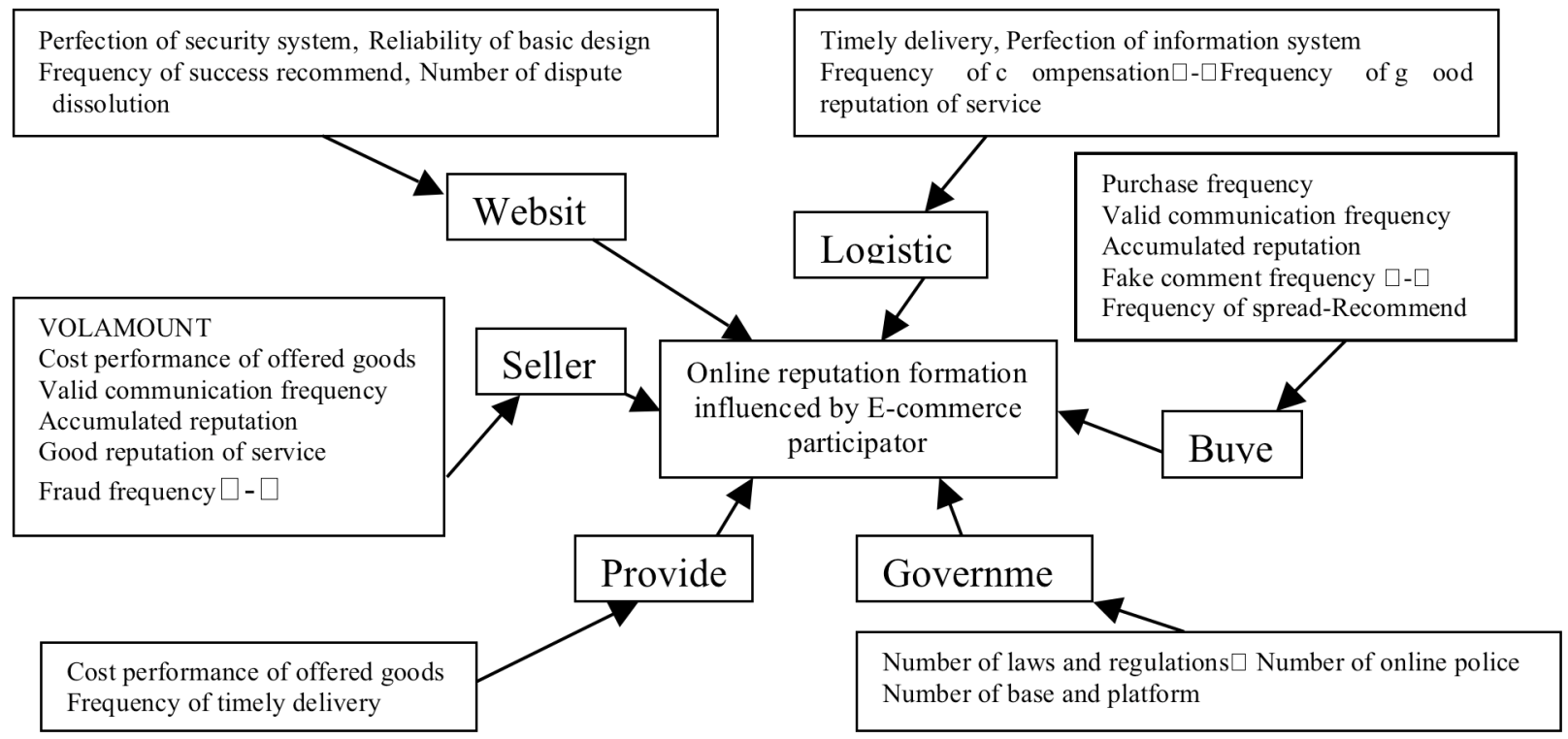

Fig. (1). The model of online reputation formation influenced by E-commerce participator.

quency of cheating can be as the efficient measure index which can influence the formation of the online reputation.

H11: the more times of clinching deals that one achieves, the more positively it influences the formation of the online reputation.

H12: the higher of a commodity's cost performance that one offers, the more positively it influences the formation of the online reputation.

H13: the higher frequency of efficient communication that one gets, the more positively it influences the formation of the online reputation.

H14: the more accumulation of credit standing value that sellers have, the more positively it influences the formation of the online reputation.

H15: the higher value of good comments for services that one gets, the more positively it influences the formation of the online reputation.

H16: the higher frequency of cheating that one gets, the more negatively it influences the formation of the online reputation.

On the side of buyer, purchase times, the frequency of efficient communication, the accumulation of credit standing value, the frequency of mendacious comments and the times of transmitting recommendation can be as the efficient measure index which can influence the formation of the online reputation. Therefore, hypothesis can be shown as following:

H21: the more times to buy, the more positively it influences the formation of the online reputation.

$\mathrm{H} 22$ : the higher frequency of efficient communication that one does, the more positively it influences the formation of the online reputation.

$\mathrm{H} 23$ : the higher of the credit standing value that buyer has accumulated, the more positively it influences the formation of the online reputation.
H24: the higher frequency of mendacious comment that one gets, the more negatively it influences the formation of the online reputation.

$\mathrm{H} 25$ : the more times for transmitting recommendation, the more positively it influences the formation of the online reputation.

On the side of website platform, the degree of the security system perfection, the reliability of basic design, the frequency of succeed recommendation and the number of solving disputes successfully can be as the efficient measure index which influence the formation of the online reputation. Therefore, the hypothesis as following:

H31: the more perfectly complete the security system, the more positively it influences the formation of the online reputation.

H32: the higher of the degree of reliability for basic design that one gets, the more positively it influences the formation of the online reputation.

H33: the higher frequency of success for recommending, the more positively it influences the formation of the online reputation.

H34: the more number of successfully solving disputes that one gets, the more positively it influences the formation of the online reputation.

On the side of the Logistics, the frequency of the in time delivering, the perfection degree of information system and the frequency of good reputation for services can be as the efficient measure index which influences the formation of online reputation. Therefore, the hypothesis as following:

$\mathrm{H} 41$ : to deliver goods more in time, which is more positively influence the formation of the online reputation.

H42: the higher degree of the information system perfectness that one completes, the more positively it influences the formation of the online reputation. 
H43: the higher frequency of compensate that one pays, the more negatively it influences the formation of the online reputation.

H44: the higher frequency of good comments for services that one gets, the more positively it influences the formation of the online reputation.

On the side of government, the number of laws and regulations, the Internet police and base platform can be as the efficient measure index which influences the formation of the online reputation. Therefore, here the hypothesis as following:

H51: the more laws and regulations are made, the more positively it influences the formation of the online reputation.

H52: the more Internet police work, the more positively it influences the formation of the online reputation.

H53: the more base-platform be built, the more positively it influences the formation of the online reputation.

On the side of supplier, the performance price ratio of goods provided and timely delivery can be as the efficient measure index which influences the formation of the online reputation. Therefore, here the hypothesis as following:

H61: the higher performance price ratio of goods provide, the more positively it influences the formation of the online reputation.

H62: the higher rate of timely delivery provide, the more positively it influences the formation of the online reputation.

\section{Sample and Data Collection}

The data used in the study are collected in the form of a questionnaire survey. The study has a universal effect as the survey questionnaire is not limited to people. Survey methodology focused on web-based survey, with the questionnaire issued by the relevant platform, group chat software in the form of surveys and sending e-mail in general research, combined with paper questionnaires and telephone inter-

Perfection of security system, Reliability of basic design

Frequency of success recommend, Number of dispute dissolution views to collect first-hand information. According to the statistics analysis, the formal survey of 366 questionnaires are collected. By screening out incomplete questionnaires and invalid questionnaires, finally get 297 effective evaluation questionnaires. Due to the effective recovery rate of $81.15 \%$, the abundance of the sample size can be ensured.

\section{Analysis Methods and Results}

First, use Cronbach's $\alpha$ to make reliability testing. We can see the Cronbach's $\alpha$ coefficients of the each factor in the Table 4

Table 4. Cronbach's $\alpha$ coefficient.

\begin{tabular}{|c|c|c|}
\hline Factor & Measuring Index Number & Cronbach's acoefficient \\
\hline \hline Seller & 6 & 0.820 \\
\hline Buyer & 5 & 0.833 \\
\hline Website & 4 & 0.795 \\
\hline Logistics & 4 & 0.804 \\
\hline Govt & 3 & 0.796 \\
\hline Providers & 2 & 0.594 \\
\hline
\end{tabular}

The result shows that the Cronbach's $\alpha$ coefficient of various factors are higher than 0.7 in addition to providers, which past the reliability testing. Since the reliability of providers is lower, the item of providers is excluded in order to ensure credibility. We can see the revised model shown in Fig. (2).

On the basis of the revised model, according to the scoring case, two factors of provider are excluded. Exploratory factor analysis is used to test the effectiveness. We can see KMO and Bartlett's testing by SPSS in Table 5.

The value of KMO is 0.633 , which is in the scope of factor analysis suitable. However, the interval of index joint degrees is $[0.496,0.756]$. Though most of the original

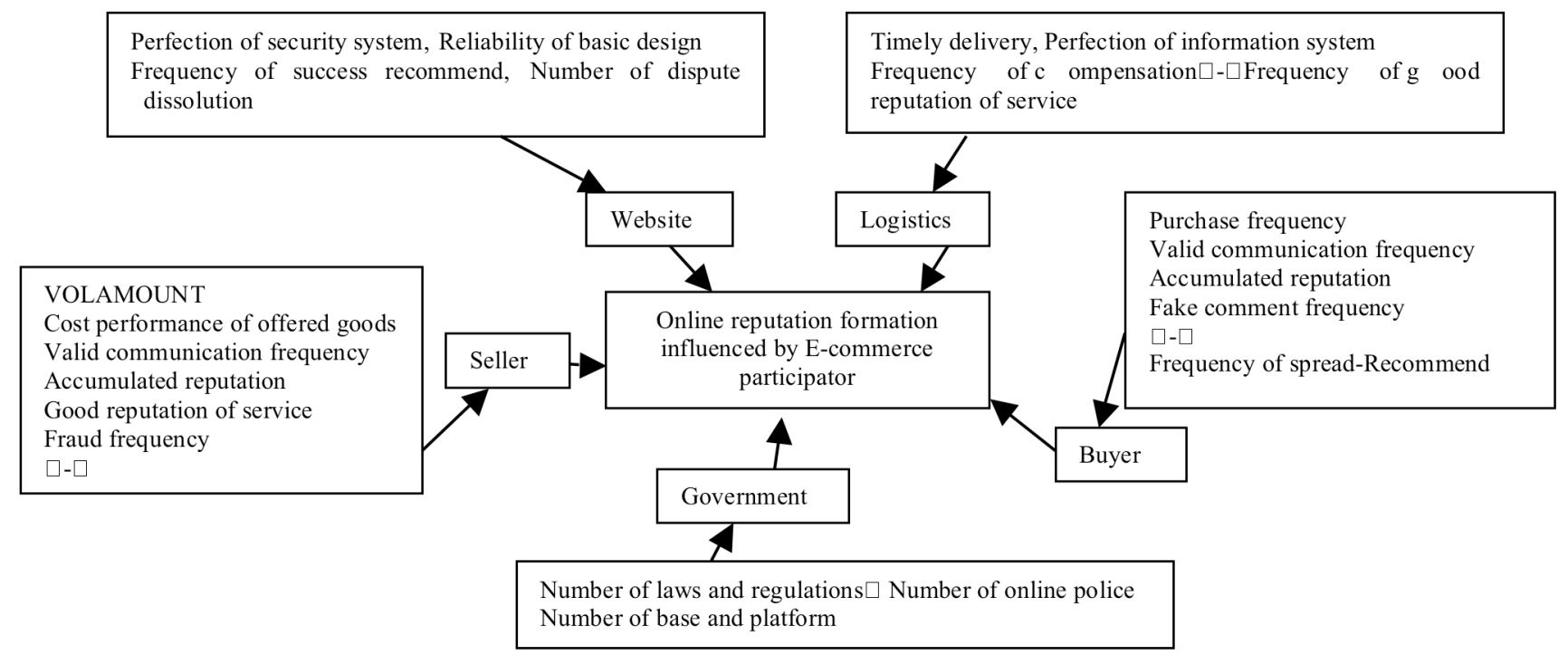

Fig. (2). The revised model. 
Table 5. KMO and bartlett's test.

\begin{tabular}{|c|c|c|}
\hline \multicolumn{2}{|c|}{ Kaiser Meyer Olkin Measure of Sampling Adequacy } & .633 \\
\hline \multirow{3}{*}{ Bartlett's Test of Sphericity } & Approx. Chi Square & 626.736 \\
\hline & Df & 104 \\
\hline & Sig. & .000 \\
\hline
\end{tabular}

indicators can be explained by common factors and also can be used to do factor analysis, but not satisfactory. As a result, the measurement index of factors should be cut. The intercommunity of the main factor variable which is less than 0.6 should be rejected, so does the factor which the little difference of factor loading. At last, the factor of Favorable comment, the frequency of effective communication, the frequency of recommendation, the number of base Platform are rejected. Data are used to do Bartlett Sphericity test again, which result shows that the test value is $2.044 \mathrm{E} 3$ and the significance probability is 0.000 , as well as the test null hypothesis is rejected. The consequence explains that there is possibility of sharing factor between each element. Meanwhile, KMO is 0.866 that means suitable to do factor analysis. We can see the test result of KMO and Bartlett's which revised again in Table 6.

Table 7. Load factor table.
In the first place, we make the maximum orthogonal rotation for variance. Assuming the number of factors extracted is 5, while the cumulative variance contribution rate is $75.637 \%$. Buyer explains the formation of e-commerce online reputation's variation which the rate is $18.397 \%$ as first factor; seller explains the formation of e-commerce online reputation's variation which the rate is $18.294 \%$ as second factor; government explains the formation of e-commerce online reputation's variation which the rate is $14.364 \%$ as third factor; logistics explains the formation of e-commerce online reputation's variation which the rate is $13.245 \%$ as fourth factor; website explains the formation of e-commerce online reputation's variation which the rate is $11.337 \%$ as fifth factor. Each factor is in descending order according to the impact of e-commerce online reputation formation. It is obviously that the biggest factor is buyer while the smallest impact is website.

Table 6. The revised KMO and Bartlett's test.

\begin{tabular}{|c|c|c|}
\hline \multicolumn{2}{|c|}{ Kaiser Meyer Olkin Measure of Sampling Adequacy } & .866 \\
\hline \multirow{3}{*}{ Bartlett's Test of Sphericity } & Approx. Chi Square & $2.044 \mathrm{E} 3$ \\
\hline & Df & 106 \\
\hline & Sig. & .000 \\
\hline
\end{tabular}

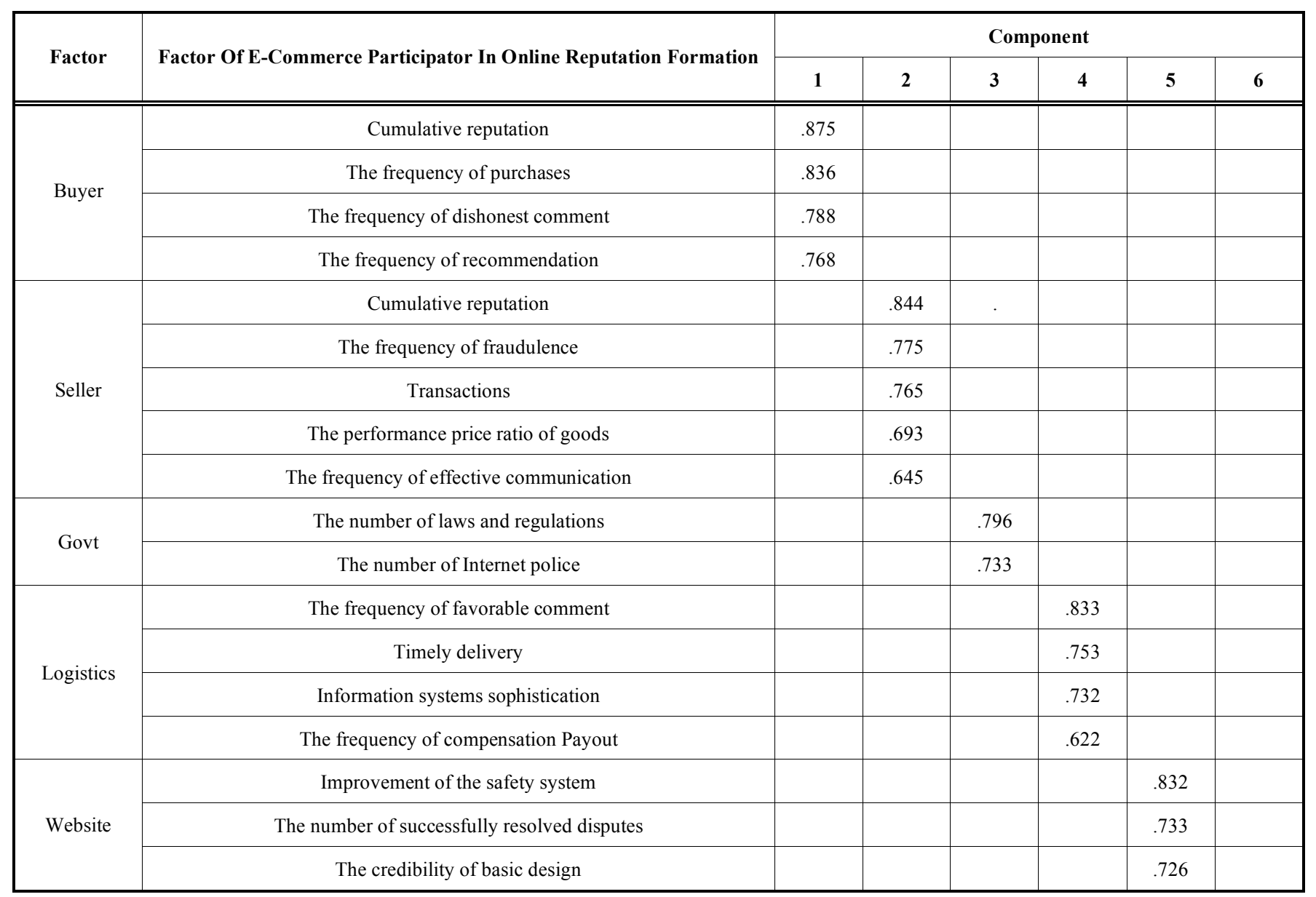




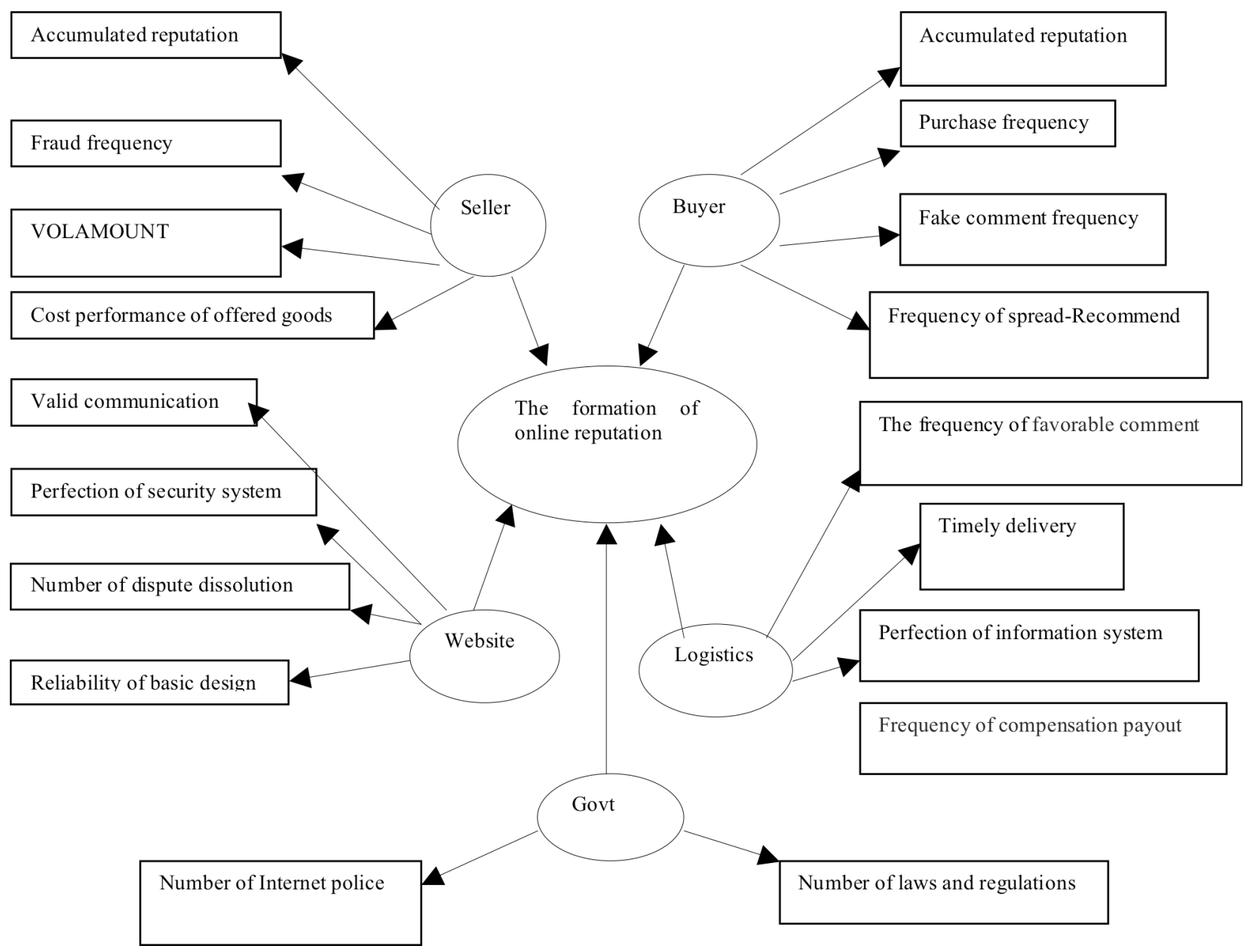

Fig. (3). Structural equation model.

Table 8. Model fitting index results.

\begin{tabular}{|c|c|c|c|c|c|c|c|}
\hline Fitting index & $\boldsymbol{\chi} \mathbf{2} / \mathbf{d f}$ & RMSEA & GFI & AGFI & NFI & IFI & CFI \\
\hline \hline Result & 1.826 & 0.053 & 0.920 & 0.642 & 0.922 & 0.898 & 0.899 \\
\hline
\end{tabular}

Table 7 shows the rotated load factor matrix. We can see that each load factor is higher than 0.6 , so we can draw the conclusion that the design of questionnaire is reasonable. As a result, every factor can be retained and has a strong explanatory power which also past validity test.

\section{Model Fitting and Results}

Via AMO software, valid data has been used for further Testing hypotheses. We can see the structural equation model in Fig. (3).

The results of model fitting index are shown in Table $\mathbf{8}$.

Table shows that $\chi 2 /$ df is 1.826 which is less than 3 in line with expectations, RMSEA is less than 0.08 which is also in line with expectations, GFI, NFI and CFI are both higher than 0.9. The data indicates that the model goodnessof-fit is favorable so that the model proved to be significant. In terms of hypothesis verification, judgment can be made by using structural equation model path estimation and the test- ing result. The result of the hypothesis testing shows in the Table 9.

\section{CONCLUSION AND OUTLOOK}

This paper normalizes the process of the formation of the e-commerce online reputation and analyzes the impact of ecommerce participator on online reputation formation. Also, the influencing factors extracted to build the index system and the initial research model of the impact of e-commerce participator on online reputation formation has been built. The paper uses empirical research methods to make the model amended three times. Ultimately, this paper draws the influence model which has 5-dimensional and 13quantitative indicators.

The related results of this study have implications for each subject of e-commerce. Primarily, the formation of online reputation is mainly influenced by five e-commerce subjects which include seller, buyer, logistics, government and websites. From the perspective of impact, the greatest degree 
Table 9. Hypothesis testing results.

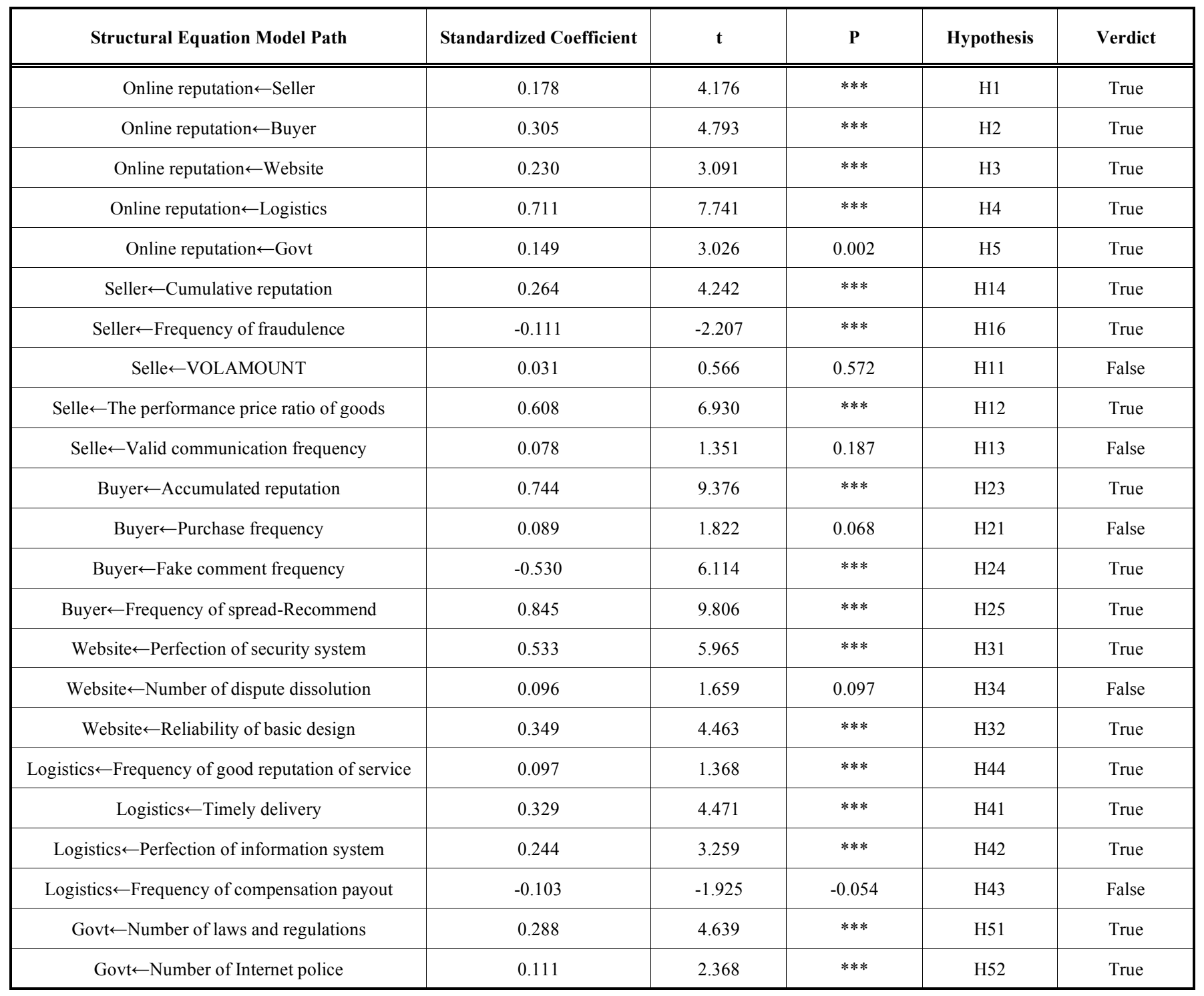

Note: ***shows significance level is 0.001

of influence on the formation of online reputation is buyer's behavior and decision-making while the minimum degree of influence is website. For another, in the mainly factors affecting the formation of online reputation from the buyer include cumulative reputation, fake comment frequency and frequency of spread-recommend; in the mainly factors affecting the formation of online reputation from the seller include cumulative reputation, fraud frequency and the performance price ratio of goods; in the mainly factors affecting the formation of online reputation from the logistics include timely delivery and perfection of information system; in the mainly factors affecting the formation of online reputation from the government include the number of Internet police and the number of laws and regulations; in the mainly factors affecting the formation of online reputation from the website include perfection of security system and reliability of basic design. Furthermore, the relationship exists among the factors which finally confirmed. From the point of future trends, how to lead these intrinsic factors that effects and relations between the five-dimensional into the model of the impact of online reputation formation in order to improve the research of the impact of e-commerce participator on online reputation formation. This will be the future research directions.

\section{CONFLICT OF INTEREST}

The authors confirm that this article content has no conflict of interest.

\section{ACKNOWLEDGEMENTS}

This study was financially supported by the Program of Liaoning Excellent Talents in University (Grant NO.WR2012003) and Liaoning Province Natural Science Foundation of China (201202169).

\section{REFERENCES}

[1] iResearch Consulting Group, China's Online Shopping Industry Annual Monitoring Report, Shanghai: iResearch Consulting Group, 2013. 
[2] M. E. Richard, and G. B. Joseph, "Manage your online reputationor someone else will," Aesthetic Surgery Journal, vol. 32, no. 5, pp. 79-86, 2012

[3] K. W. Corriore, "Online trust: Concepts, evolving themes, A model," International Journal of Human Computer Studies, vol. 58, no. 6, pp. 737-758, 2003.

[4] D. L. Ang, "To Trust or Not to Trust? A Model of Internet Trust from the Customer Point of View," In: 14th Bled Electronic Commerce Conference, Bled: Solvenia, 2001.

[5] D. Chen, "Consumer needs online reputation management," Worldwide Videotex Update, vol. 31, no. 5, pp. 66-74, 2012.

[6] P. Mathur, and J. Black, "The impact of social media usage on consumer buying behavior," Advances in Management, vol. 5, no. 1, pp. 14-22, 2012

[7] M. Fang, R. Lu, and W. Wu, "A review on the influence factors of consumer trust based on E-commerce," Journal of Intelligence, vol. 29, no. 6, pp. 195-198, 2010.

[8] X. Ding, Research on Influencing Factors of Consumers' Trust in Online Sellers: (Master dissertation), Xiamen: Xiamen University, 2008.

[9] Q. Su, Z. Li, and Y. Cui, "An empirical analysis on the antecedents of internet customer behavior," Systems Engineering, vol. 25, no. 2, pp. 1-6, 2007.

[10] C. McKnight, "Initial trust formation in new organizational relations," Academy of Management Review, vol. 23, no. 3, pp. 473490, 1998.
[11] Y. Zhu, L. Liu, and W. Zhang, "Study of trust model in online reputation system," Control and Decision, vol. 22, no. 4, pp. 413417, 2007.

[12] D. Yuan, Research on Theory and Model of the E-commerce Participator Credit Risk Evaluation: (PhD dissertation), Beijing: Beijing University of Posts and Telecommunications, 2010.

[13] C. Li, and C. Liang, "Muti-dimensionality reputation evaluation model for C2C E-commerce," Chinese Journal of Management, vol. 2, pp. 204-211, 2012.

[14] X. Zhao, C. Zhao, and Y. Shen, "Empirical study on the effect of E-commerce site institution on trust," Chinese Journal of Management, vol. 5, pp. 715 722, 2012.

[15] W. Tang, "Design and implement of C2C e-commerce trust model," Computer Engineering and Application, vol. 48, no. 1, pp. 94-97, 2012.

[16] Y. D. Wang, "An overview of online trust: Concepts, elements, and implications," Computer in Human Behavior, vol. 11, pp. 1-21, 2004.

[17] G. L. Bellman, and E. J. Lohse, "Predictors of online buying behavior," Communications of the ACM, vol. 42, no. 2, pp. 32-38, 1999.

[18] S. Zhang, X. Dong, and Y. Guan, "Synonym recognition based on user behaviors in E-commerce," Journal of Chinese Information Processing, vol. 26, no. 3, pp. 79-85, 2012.

[19] R. Goldsborough "Online reputation management is new aspect of good PR," Technology Today, vol. 9, p. 16, 2012.

Received: October 16, 2014

Revised: December 03, 2014

Accepted: December 09, 2014

(C) Yu and Wei; Licensee Bentham Open.

This is an open access article licensed under the terms of the Creative Commons Attribution Non-Commercial License (http://creativecommons.org/licenses/by-nc/3.0/) which permits unrestricted, non-commercial use, distribution and reproduction in any medium, provided the work is properly cited. 